\title{
GRAMSCI: UM OLHAR MARXISTA SOBRE O FENÔMENO RELIGIOSO
}

Gramsci: a marxist look on the religious phenomenon

\author{
Allan Azevedo Andrade ${ }^{1}$ \\ Fernando Arthur Freitas Neves ${ }^{2}$
}

Resumo: O presente trabalho tem como escopo destacar a análise marxista de Antonio Gramsci sobre o fenômeno religioso, sem desconsiderar sua perspectiva historicista. Em seus escritos, os chamados Cadernos do Cárcere, são encontradas contribuições muito importantes para o estudo da religião, particularmente, quando circunscreveu seu entendimento do evento como estrutura, irrupção inovadora, profundas transformações, desintegração e transição estrutural. Ao invés de se aproximar de um pretenso objetivismo, Gramsci considera a dimensão subjetiva ao desenvolver sua estratégia sobre o papel dos intelectuais, a luta cultural, e o papel do proletariado ao intervir na elaboração da estrutura em superestrutura na consciência do indivíduo, se opondo a história especulativa e teológica ao passo que busca compreender o papel contemporâneo da Igreja e a importância da cultura religiosa entre as camadas populares. Sua abordagem oferece outra qualidade para a questão da subjetividade ao torná-la um par da realidade material, distanciando-se da compreensão metafísica rasa de duas esferas.

Palavras chave: Religião; Gramsci; Igreja.

Abstract: The present work aims to highlight Marxist analysis by Antonio Gramsci on the religious phenomenon, without disregarding his historical perspective. In his writings, the so-called Cadernos do Cárcere, are very important contributions are found for the study of religion, especially circumscribed understanding of the event is as a structure, innovative outbreak, profound transformations, disintegration and structural transition. Rather than approaching an alleged objectivism, Gramsci considers the subjective dimension when developing his strategy on the role of intellectuals, the cultural struggle, and the role of the proletariat and to intervene in the elaboration of the structure of the superstructure in the consciousness of the individual, opposing speculative and theological history while seeking to understand the contemporary role of the Church and the importance of religious culture among the popular strata. His approach offers another quality to the question of subjectivity by making it in tune with material reality, thus distancing itself from the shallow metaphysical understanding of two spheres.

Keywords: Religion; Gramsci; Church.

\footnotetext{
${ }^{1}$ Professor da Secretaria de Educação do Pará, doutorando pelo programa de História Social da Universidade Federal do Pará. Mestre em História Social da Amazônia. E-mail: allan.andrade89@hotmail.com

${ }^{2}$ Professor do curso de Graduação e Pós-Graduação do curso de História da Universidade federal do Pará. Doutor em História pela Pontícia Universidade Católica de São Paulo E-mail: fafn@ufpa.br
} 


\section{Introdução}

Ao olhar para as obras de Karl Marx, é possível identificar alguns trabalhos abordando a religião, ainda que seu foco de análise tenha sido a produção da vida material, sobretudo, relacionado à política e a economia. Seus estudos são tão ricos que, seja olhando para os poucos trabalhos que tratam especificamente da religião, seja olhando para sua produção como um todo, conseguimos extrair pistas capazes de auxiliar na pesquisa do fenômeno religioso. Não por acaso, alguns autores inspirados nas leituras marxistas são relevantes para os avanços nesse campo de estudo.

A contribuição de Marx para o entendimento da religião vai muito além da ideia da religião como "o ópio do povo"3, proferida em Crítica da filosofia do direito de Hegel, de 1843. Isso porque, a partir de 1846, com a elaboração de A Ideologia Alemã, - já em uma fase madura, conforme está cristalizado entre seus estudiosos que classificaram suas obras - Marx defende que a análise da religião requer a aproximação como uma das várias formas de ideologia, isto é, "da produção espiritual de um povo, da produção de ideias, representações e consciência, necessariamente condicionadas pela produção material e as correspondentes relações sociais”. (LÖWY, 2007).

Assim, na concepção marxista da história, as formas de consciências que constituem a sociedade - política, filosofia, metafísica, religião e estética - não podem ser entendidas desconectadas da produção material desenvolvida pelos homens. Essa é uma crítica extremamente valiosa para penetrar no pensamento de Gramsci. Essa valorização fica muito mais evidente quando considerado o rito religioso como uma expressão viva e concreta da validação da crença. O que significa reconhecer o fenômeno religioso como a conjunção orgânica entre geral e específico, entre concreto e abstrato.

\footnotetext{
${ }^{3}$ Além de o termo ter sido interpretado pejorativamente - visto que Marx escreveu essa frase compreendendo a religião como a alienação da essência humana e não como uma conspiração clerical - o próprio Marx não é o autor da expressão que já circulava pela Europa nos escritos de Immanuel Kant, J. G. Herder, Ludwig Feuerbach, Bruno Bauer, Moses Hess e Heinrich Heine. Ademais, na ocasião dessa elaboração, Marx declamou uma análise pré-marxista, a-histórica, e sem referência a classes. Apenas posteriormente, em A Ideologia Alemã de 1846, é que deu início o estudo marxista da religião como uma realidade social e histórica. (LÖWY, 2007).
} 
Intelectuais como Friedrich Engels, Karl Kautsky, Ernst Bloch e Walter Benjamin se aventuraram na tarefa de analisar a religião com as ferramentas do marxismo. Todavia, entre os vários pensadores influenciados pela teoria marxista, Antonio Gramsci foi o intelectual mais aplicado no estudo do fenômeno religioso, sobretudo do cristianismo, distanciando-se da visão metafisica de Kautsky na obra $A$ Origem do Cristianismo, que buscava captar a importância desta categoria na elaboração de sua cosmovisão durante sua trajetória de vida, ligada à militância comunista, propondo uma reinvenção do marxismo e das potencialidades contidas nas obras de Marx.

Se na década de 1840, a obra A Essência do Cristianismo de Ludwig Feuerbach havia mobilizado o pensamento de Marx para demonstrar como funciona a ideologia alemã, partindo da premissa exatamente da religião e da necessidade da crítica religiosa converter-se na crítica do direito e, por conseguinte, na crítica da propriedade privada, Gramsci volta ao problema da religião ao perceber a importância desta na derrota dos levantes de trabalhadores italianos e das lideranças socialistas, comunistas, socialistas cristãs e liberais contra o fascismo. Sem dúvida, o peso orgânico do Vaticano como um "Estado/Igreja", dentro do Estado italiano, revelou a opção decidida que a hierarquia religiosa católica fez ao lado do fascismo, quando obrigou o Partido Popular, fundado por um padre e outros religiosos católicos, a abdicar de seguir como um projeto político independente como havia se constituindo entre os liberais e os comunistas, segundo a interpretação feita da encíclica Rerum Novarum de Leão XIII, em 1891. (LEÃO XIII, 1997). Foram abandonados e oprimidos pela Igreja para não se confundirem com as opções apresentadas por liberais e comunistas de um lado, em oposição ao que parecia ser a segurança e a manutenção do status quo da Igreja em concordata com o estado fascista italiano, posteriormente celebrado nos Acordos de Latrão ${ }^{4}$. Nessa trama queremos extrair algumas referências para descortinar o aspecto religioso na sociedade civil, em cruzamento com a religião no corpo do Estado.

Nascido na Sardenha, Itália, em 1891, Gramsci foi filósofo, jornalista, crítico literário e político italiano. Além disso, foi membro-fundador e secretário-geral

\footnotetext{
${ }^{4}$ O Tratado de Latrão, ou Tratado de Santa Sé ou Tratado de Roma-Santa Sé foi o acordo assinado entre o Reino da Itália e a Santa Sé (Igreja Católica) em 1929. Nesse acordo, foi solucionada a Questão Romana, dessa forma, as disputas territoriais existentes entre as duas partes desde o século XIX tiveram fim. Além disso, foi criado oficialmente o Estado da Cidade do Vaticano, um pedaço de terra soberano sob domínio da Igreja.
} 
do Partido Comunista da Itália, e deputado pelo distrito do Vêneto. Tendo sido preso pelo governo fascista de Benito Mussolini, em 1926. Em situação extremamente penosa na cadeia, sofrendo vigia constante, o que lhe suscitava um cuidado redobrado para não comprometer seus camaradas, familiares e a si mesmo, Gramsci obriga-se revisar os dramas de seu tempo e como as lutas sociais acabaram gerando um regime profundamente anti-humano como era o fascismo. Ele entrou em contato com muitas obras de inspiração liberal e as insuficiências destas para opor-se a violência da exploração capitalista que havia gerado mais medo em toda sociedade, especialmente naqueles segmentos das classes médias, enquanto as classes subalternas estavam elaborando um outro modo de organização social. Esse arcabouço foi o substrato para redação dos textos reunidos nos Cadernos do Cárcere $^{5}$, residindo nesses escritos às contribuições mais importantes sobre religião.

De tal forma, o presente trabalho se dedica a analisar a colaboração marxista para a análise das temáticas religiosas sob o olhar de Antonio Gramsci, buscando em sua visão, as contribuições sobre o estudo da religião e, consequentemente, seu entendimento do evento como estrutura, irrupção inovadora, as profundas transformações, desintegração e transição estrutural; típico da maneira marxista de pensar a história. (REIS, 2000).

\section{GRAMSCI E O HISTORICISMO}

Segundo Luciano Gruppi (1991), nem Marx, nem Engels, tão pouco Lênin definem o marxismo como historicismo. O responsável por essa associação entre marxismo e historicismo foi Gramsci, contudo, diferente do historicismo da Alemanha, o marxismo concebe uma concreticidade histórica que possui elementos que se repetem (leis, estruturas), permitindo entender os elementos constituintes do evento histórico singular, escapando do relativismo que pesa sobre o historicismo alemão.

\footnotetext{
${ }^{5}$ Os Cadernos do Cárcere (Quaderni del carcere, em italiano), foram originados em uma série de anotações fragmentadas, posteriormente reunidas em um conjunto de 29 cadernos escritos por Gramsci no período em que foi prisioneiro na Itália, entre 1926 e 1937. Os Cadernos começaram a ser redigidos, de fato, em fevereiro de 1929, no cárcere de Turi, nas imediações de Bari, pouco depois de Gramsci ter obtido autorização para estudar e escrever. A cunhada Tatiana (Tania) Schucht e o economista Piero Sraffa, professor em Cambridge, foram importantes na preservação e o salvamento dos Cadernos, depois da morte de Gramsci. É também a Tatiana que se dirige a maioria das Cartas do cárcere, que, junto com os Cadernos, constituem o legado mais significativo do político e pensador.
} 
Concernente a esse pensamento, Gramsci entende que a além de ser a teoria das contradições existentes na história e na sociedade, a filosofia da práxis ${ }^{6}$ é "o historicismo absoluto, a mundanização e terrenalidade absoluta do pensamento, um humanismo absoluto da história”. (GRAMSSCI, 1999, p. 155). Destarte, a filosofia da práxis se apresenta no estudo concreto da história passada e na atividade atual de criação de uma nova história. Dentro dessa lógica, a filosofia da práxis não entende o ser separado do pensar, reduzindo a "especulatividade" aos seus limites (negando que a "especulatividade" seja o aspecto essencial da filosofia), caracterizando-se, segundo Gramsci, como a metodologia histórica mais adequada a realidade.

Além de seguir essa tendência, Gramsci também foi fortemente influenciado pelo pensamento intelectual de Benedetto Croce, referência dentro da escola idealista italiana. Segundo Gramsci, essa corrente intelectual se afastava do núcleo revolucionário de referência marxista - embora se aproximasse do historicismo ao superar o especulativismo abstrato ligado à tradição idealista -, mesmo assim, ele reconhece o mérito de Croce no historicismo, isto é, a concepção de que todo o real é história.

Gramsci entende que o pensamento de Croce deve ser estudado com a atenção, pois representa essencialmente uma reação ao "economicismo" e ao mecanicismo fatalista, ainda que se apresente como superação destrutiva da filosofia. Contudo, a oposição entre o croceanismo e a filosofia da práxis se localiza no caráter especulativo do croceanismo. Dessa forma, Croce entende o real como espírito, logo, prescinde daqueles que são sujeitos vivos da história, enquanto Gramsci se afasta de determinismos teóricos que simplificavam as explicações do mundo social em favor da dimensão econômica.

\begin{abstract}
A pretensão (apresentada como postulado essencial do materialismo histórico) de apresentar e expor qualquer flutuação da política e da ideologia como uma expressão imediata da infra-estrutura deve ser combatida, teoricamente, como um infantilismo primitivo, ou deve ser combatida, praticamente, com o testemunho autentico de Marx, escritor de obras políticas e históricas concretas. (GRAMSCI, 1999, p. 238).
\end{abstract}

Nessa lógica de pensamento, Gramsci leva em consideração a subjetividade ao desenvolver sua ideia sobre o papel dos intelectuais, a luta cultural, e o papel do

\footnotetext{
${ }^{6}$ Gramsci usa frequentemente o termo filosofia da práxis para indicar o marxismo devido a uma prudência conspirativa oriunda do ambiente de perseguição causado pelo governo fascista.
} 
proletariado ao intervir na elaboração da estrutura em superestrutura na consciência do indivíduo, significando “também, a passagem do 'objetivo ao subjetivo' e da necessidade à liberdade" 7 . Ademais, o pensamento gramsciniano incorpora a crítica croceana sobre o racionalismo, imanente às correntes historiográficas e à filosofia da história.

Apesar de absorver alguns aspectos do pensamento croceano, Gramsci busca demonstrar a incapacidade de Croce em levar a termo a sua proposição metodológica historicista. Ao realizar sua crítica, Gramsci aponta a dialética croceana como um artifício racionalista, isto é, a história possui regras pré-determinadas que são seguidas em comum acordo pelos opositores históricos, aceitando a dialética desde que seja preservado o Estado Liberal como terreno de conflitos entre "tese" e "antítese":

Como exigir que as forças em luta "moderem" esta luta dentro de certos limites (os limites da conservação do Estado liberal), sem com isso cair no arbitrário ou na meta preconcebida? Na luta, "os golpes não são dados de comum acordo", e toda antítese deve necessariamente colocar-se como antagonista radical da tese, tendo mesmo o objetivo de destruí-la e substitui-la completamente. (GRAMSCI, 1999, p. 396).

$\mathrm{Na}$ condição militante, Gramsci entende como essencial o conhecimento da história como disciplina e como processo para alcançar seu projeto revolucionário. Portanto, contrariando análises abstratas e a-históricas do mundo social, ele afirma que o marxismo é uma historicismo absoluto, na medida em que para ele, nada existe fora da história, recuperando a centralidade da história no projeto teórico-político marxista, possibilitando compreendê-lo para que assim se possa superar o formalismo racionalista. Logo, a partir desse paradigma, inviável fora da história, conceitos como hegemonia, sociedade civil, bloco histórico, intelectuais orgânicos e tradicionais, são entendidos como resultado do seu pensamento historicista.

Dentro dessa ideia historicista, Gramsci teoriza o conceito de hegemonia como sendo a capacidade de união por meio da ideologia mantendo unido o bloco social marcado por contradições de classe. Isto é, a noção de hegemonia propõe um distanciamento da ideia da determinação da estrutura sobre a superestrutura, mostrando a centralidade das superestruturas na análise das sociedades avançadas. Com isso, a

\footnotetext{
${ }^{7}$ GRAMSCI, Antonio. Concepção dialética da história. 3. ed. Rio de Janeiro: Civilização Brasileira, 1978. p. 53.
} 
sociedade civil adquire um papel central, bem como a ideologia, que aparece como constitutiva das relações sociais.

Assim, através da ação política, ideológica e cultural, o grupo hegemônico consegue manter articulado um grupo de forças heterogêneas traduzindo-se não apenas sobre estrutura econômica e sobre organização política da sociedade, mas também sobre a forma de pensar, isto é, uma reforma intelectual e moral ${ }^{8}$. A Igreja católica é um exemplo dessa hegemonia teorizada por Gramsci, visto que esta busca conservar o bloco constituído pelas forças dominantes, forças subalternas, intelectuais e pessoas simples; realizando grande investimento na esfera intelectual e moral.

A partir disso, a hegemonia tende a construir o bloco histórico, formando uma unidade de forças sociais e políticas diferentes, conservando-as juntos por meio da concepção de mundo que ela difundiu. O conceito de bloco histórico, entendido como complexo de estruturas materiais e superestruturas ideológicas que se condicionam mutuamente, é desenvolvido por Antonio Gramsci - inspirado em Georges Sorel, embora bastante diverso do conceito soreliano - tendo em vista o nexo vital entre base econômica e superestrutura ideológica. (GRAMSCI, 1999). Dessa forma, a concepção gramsciniana de bloco histórico compreende que:

(...) as forças materiais são o conteúdo e as ideologias são a forma, distinção entre forma e conteúdo puramente didática, já que as forças materiais não seriam historicamente concebíveis sem forma e as ideologias seriam fantasias individuais sem as forças materiais. (GRAMSCI, 1999, p. 238).

Enquanto marxista, Gramsci se opõe a história especulativa e teológica (própria do idealismo como um todo), e a Croce, que abstrai o aspecto ético e político, cultural e político da história, separando-o de sua base, caracterizando em uma substância que vive em si mesma, reduzindo a história a uma dimensão conceitual e intelectual. De maneira diferente, Gramsci, a partir de uma concepção imanentista, se apoia no conceito de estrutura enquanto elucidação das formações histórico-sociais, consequentemente, entendendo que não se pode apartar a superestrutura da estrutura, ou seja, o momento ético-político, e a cultura ser separada da base econômica. (VIEIRA, 1995). Tendo em vista isso, Gramsci entende que as tendências estruturais não eram autônomas frente às ações humanas, logo, as estruturas seriam resultado do processo

\footnotetext{
${ }^{8}$ Segundo Gramsci (1999): “A realização de um aparelho hegemônico, enquanto cria um novo terreno ideológico, determina uma reforma das consciências e dos métodos de conhecimento, e um fato de conhecimento, um fato filosófico."
} 
histórico, no qual não há estrutura fora da ação humana, em conformidade com a premissa de que os homens fazem a história diante das condições históricas em que se encontravam, e não de acordo com suas cabeças.

\section{FENÔMENO RELIGIOSO SOB O OLHAR DE GRAMSCI}

Suportar o peso assombroso da existência foi uma tarefa em grande medida absorvida pela religião como condição própria dessa mesma resistência do humano no quotidiano, para não sucumbir diante da contingência por um lado, enquanto se amálgama na estrutura da reprodução material e espiritual da sociedade. Essas críticas já estavam maduras a época de Marx, quando este percebeu as referências de Ludwig Börne e Moses Hess na década de 1840 ao denunciarem como a condição de infelicidade e exploração a que os homens estavam sendo submetidos, ${ }^{9}$ notadamente nas classes subalternas, ao prescindirem de recursos físicos para alterarem sua condição, sempre terão o arcabouço da religião como amparo para rogar redenção. Se não for nesse mundo... há de ser no outro.

Entre os pensadores marxistas que estudam a religião, Antonio Gramsci é um dos mais destacados, uma vez que, diferente de Friedrich Engels - que se dedicou mais aos protestantes - ou Karl Kautsky - que buscou entender melhor o cristianismo primitivo -, preferiu entender a função da Igreja Católica na sociedade capitalista moderna, buscando a compreensão do seu papel contemporâneo e a importância da cultura religiosa entre as camadas populares, ao invés de se interessar pelo cristianismo primitivo ou pelos hereges comunistas da época medieval, recusando mecanicismo vulgar que procura explicação imediata de todos os fatos políticos e ideológicos em determinantes econômicas.

Baseado nas leituras das obras de Marx, Gramsci compreende a religião como portadora das contradições que atravessam a sociedade de classe, tanto como força revolucionária, quanto como expressão alienante das massas. Tendo em vista isso, ele conceitua a religião como sendo a crença na existência de uma ou diversas divindades transcendentais, envolvendo o sentimento dos homens de que dependem essas divindades que governam a vida do cosmo, ao passo que proporciona a presença de um sistema de cultos dos seres humanos relacionados aos seres divinos. (GRAMSCI, 2007).

\footnotetext{
${ }^{9}$ LÖWY, Michael. Marx e Engels como sociólogos da religião. Lua Nova, São Paulo, n. 43, p. 157-170, 1998. Disponível em: <http://www.scielo.br/scielo.php?script=sci_arttext\&pid=S010264451998000100009\&lng=en\&nrm=iso>. Acesso em: 29 de abril de 2020.
} 
Nos nossos dias, percebemos uma gama de expressões religiosas, cujo ritos são apresentados como renovados ou inspirados em uma referência imanente da região como um dado natural. Parte daqueles que se afastaram da religião, a elas recorrem quando confrontados com a possibilidade de ver negada a sua satisfação em um dado momento objetivo das situações de fragilidades apresentadas durante a vida. Isso porque, a recusa em desconstruir a própria possibilidade de existência de todo o arsenal religioso, incluso a possibilidade de redenção, fraturaria todo tecido sobre o qual se apoia qualquer possibilidade de realização. Para superar essa armadilha, o humano absorveu a resposta da promessa como uma revelação. Obviamente, esta assimilação não é homogênea, antes, ela encerra diferentes termos como são experimentadas as religiões nos marcos culturais, ambientais, étnicos e sociais de classe, fração de classe.

As concepções de mundo organizam os significados que se têm da vida. Repousa sobre eles a intencionalidade de justificar o porquê de as coisas serem como são e não de um outro modo qualquer. Trata-se de um imperativo de ordem para conseguir legitimar as relações sociais estabelecidas.

A virada do milênio parecia ter colocado a religião como algo adstrito ao passado, portadora de uma capacidade de satisfação quando a humanidade ainda não teria alcançado a sua a idade adulta. Diante da progressiva expansão da ciência e sua capacidade de formatar, empreender e exercer domínio crescente, mobilizando variado corpo de conhecimentos validados desde a experimentação à indução em suas muitas formas de compreender e interpretar o presente, alargaram o processo de religião civil, confrontando o paradigma religioso, levando-o ao que parecia ser o seu ocaso; entretanto nosso tempo presente manifesta a prodígio da religião como possibilidade de repensar o quanto ela comporta de Inter atuação de presente no/do tempo e continua a ser um eficiente vetor de identificação e significação com a realização plena. Esta condição habilita então a retornarmos as reflexões sobre a importância do fenômeno religioso na caminhada da condição humana.

Dentre as contribuições de Gramsci, nos deteremos na apropriação feita da cosmovisão de Marx superando a determinação negativa de ideologia como mera roupagem enganosa da realidade. Com efeito, usa da filosofia da práxis para interrogar sua própria concepção de ideologia, pois para ele, esta é historicamente necessária, na medida em que tem uma validade "psicológica", isto é, elas "organizam" as massas humanas formando o terreno no qual os homens se movimentam, adquirem consciência 
de sua posição, lutam etc. (GRAMSCI, 1999). Além disso, ele entende a ideologia, enquanto superestrutura, não como diretamente determinada pela infraestrutura econômica, mas sim como visão de mundo que compreende vários graus culturais correspondentes aos grupos sociais nos quais está inserida, não se configurando um conjunto cultural coerente. É essa heterogeneidade ideológica que explica a articulação de subconjuntos culturais ligados aos distintos grupos sociais no interior de uma mesma religião.

Ao invés de voltar sua atenção para a religião como concepção de mundo etérea ou abstrata, desconectada das condições materiais na qual esta intervém, Gramsci se dedica a analisar conduta prática correspondente a cada religião. Nessa perspectiva, ele percebe como em dado momento histórico a religião pode conduzir a comportamentos opostos daqueles enunciados em sua doutrina. Isso fica claro quando percebe a atitude ativa e progressista do cristianismo primitivo ou do protestantismo, bem como a atuação conservadora do cristianismo jesuitizado.

No que tange a análise da reforma protestante, Gramsci se apoia em Max Weber, entendendo que a transformação da doutrina calvinista da predestinação em um impulso para a iniciativa prática, é um claro exemplo da mudança de um ponto de vista do mundo para uma norma prática de comportamento. Nesse sentido, Gramsci supera a inclinação economicista do marxismo vulgar, insistindo no papel historicamente produtivo de ideias e representações, utilizando as ideias de Webber como sustento. (LÖWY, 2007). Não por acaso ele entende a reforma protestante como o primeiro movimento nacional-popular, considerando as reflexões weberianas na busca por se dissociar do economicismo, dando valor as ideias, ao passo que interpreta a concepção de mundo como fomentadora das práticas de comportamento - mesmo que bastante criticado por outros marxistas -, tal como o caso o protestantismo calvinista e o alavancamento do capitalismo.

Além de inovar na análise sobre a reforma protestante, Gramsci também apresenta contribuição referente ao estudo do catolicismo durante a história, considerando diferenças internas da Igreja Católica de acordo com orientações ideológicas (moderna, liberal, jesuítica e correntes fundamentalistas no interior da cultura católica), e as distintas classes sociais ao afirmar a existência de "um catolicismo para os camponeses, um para a pequena burguesia e trabalhadores urbanos, um para a mulher, e um catolicismo para intelectuais" como afirma Gramsci (1999, p. 
115), reforçando sua ideia de que toda religião é uma multiplicidade de diferentes e às vezes contraditórias religiões.

Ao dedicar maior atenção à religião católica, Gramsci destaca que além de entendê-la como um tipo particular de ideologia, é imprescindível estudar a Igreja como aparelho ideológico, subordinando assim a análise da ideologia ao conceito de hegemonia. No pensamento gramsciniano são identificados dois tipos de intelectuais ${ }^{10}$ : o orgânico e o tradicional. $O$ intelectual orgânico é definido como um organizador da produção de um novo modo cultural, enquanto o intelectual tradicional é caracterizado por fazer referência ao passado no intuito de dar continuidade a sua independência e hegemonia.

Nessa condição, a Igreja seria um corpo formado por casta de "intelectuais tradicionais" - o clero e os intelectuais católicos seculares -, isto é, intelectuais que expressam saudosismo feudal e não organicamente ligados a nenhuma classe social moderna.

\begin{abstract}
A mais típica destas categorias intelectuais é a dos eclesiásticos, que monopolizaram durante muito tempo (numa inteira fase histórica que é parcialmente caracterizada, aliás, por este monopólio) alguns serviços importantes: a ideologia religiosa, isto é, a filosofia e a ciência da época, através da escola, da instrução, da moral, da justiça, da beneficência, da assistência, etc. (GRAMSCI, 1982, p. 05)
\end{abstract}

Dentro dessa lógica, Gramsci (2007) propõe uma explicação que atualiza o exercício do poder de Estado ao conferir complementaridade ao conjunto da sociedade política e sociedade civil, responsáveis pela manutenção e reprodução viva a garantir a constituição do Estado, favorecendo a pactuação das forças sociais estabelecidas para dirigir sua hegemonia.

Durante a Idade Média foi bastante evidente essa composição política entre a Igreja e a aristocracia no ocidente. Contudo, a descentralização do exercício do poder entre as relações de suserania foi confrontada pela produção de riqueza, cujo cerne precisava reforçar o domínio sobre os camponeses, obrigando ao senhor mais forte a submeter os outros senhores, incluso o alto clero da Igreja. Esta operação representou o sacrifício do poder, para manter o efetivo poder. Em consonância com essa alteração nas relações sociais, houve uma reelaboração da produção de ideias que questionaram a

\footnotetext{
${ }^{10}$ Para Gramsci (1982), os intelectuais são aqueles que elaboram a ideologia, caracterizando-se por serem os agentes da hegemonia da classe dominante. Com isso, o intelectual atua não apenas no campo econômico, mas também político e social, ou seja, é aquele capaz de elaborar uma interpretação coerente do mundo e conduzir a ação, em meio a uma sociedade caracterizada pelas distinções e divisões sociais.
} 
legitimidade e a legalidade do poder existente. À guisa de recusa do fracionamento do poder conferido gerou um outro ethos para direção política da sociedade insurgindo-se contra o domínio papal nas relações nacionais.

Se anteriormente a doutrina das duas espadas havia conseguido plena adesão e justificação com o Papa Inocêncio III, as ameaças de fragmentação do poder corroboraram para sua superação, não sem antes atestarem muitas lutas durante quase cinco séculos até o efetivo domínio do rei sobre a aristocracia, enquanto secundava a Igreja do exercício da violência estatal, confiando a esta um domínio singular na elaboração da cultura.

Pelos muitos registros sobre a caminhada da humanidade no ocidente, a Igreja acreditava candidatar-se naturalmente, pois sua legitimação seria atemporal. Para cumprir esta função de reprodução do imaginário social, ela considerava-se como a única instituição a merecer crédito para comprometer o humano com sua teleologia, fundando sua auto legitimação, assim reconhecida, como a responsável por assegurar esse encontro do início com o fim. Realização escatológica fruto da Redenção.

Confiando nessa tradição, a Igreja buscou manter o monopólio dessa condição de intelectual coletivo, comprometida com a reprodução material e moral da ordem em vigor, embora fosse questionada em diferentes momentos e formas sobre esse seu direito de exclusividade. A irrupção da reforma protestante colocou uma cunha contundente nessa capacidade de detenção desse monopólio. Devendo disputar esse lugar com outras igrejas cristãs e demais instituições que se consolidaram na modernidade, a Igreja de Roma buscou ocupar-se da validação de um lugar específico para seguir nessa condição de sagração da ordem, depois de ter sido alijada do exercício direto do poder de Estado. Se é verdade que a Igreja foi desidratada nessa concorrência com o Estado, nem por isso ela aceitou qualquer lugar para ratificar o seu ideal de legitimação.

Nesse sentido, a Igreja seria integrante da sociedade civil enquanto aparelho ideológico, tendo a função de manter a hegemonia da classe fundamental sobre os outros grupos sociais. No entanto, essa condição caracteriza-se por uma maior autonomia com relação à estrutura social do que a sociedade política. 
Segundo Eric Hobsbawm (1998), a relação recíproca entre base ${ }^{11} \mathrm{e}$ superestrutura - levando em consideração que a superestrutura assume papel autônomo em relação a base - fornece as bases para o desenvolvimento de determinada cultura, portanto, é essencial estudar a produção da vida material para entender as práticas culturais. Diferente dos grupos sociais fundamentais, a relação entre os intelectuais e o mundo da produção não é imediata, mas sim "mediatizada" pelo conjunto das superestruturas. (GRAMSCI, 1982, p. 10).

O relacionamento dos intelectuais com a expressão material da vida é extremamente dinâmico, porém não é desprovido das próprias ferramentas das quais se utiliza para externar, em diferentes aportes, os objetos a lhes dar concretude, seja sob a forma de imagens, ideias, sentimentos, sentidos e valores, cujo o propósito é significar a ventura da humanidade. Essas palavras grafadas aqui neste papel, conformadas nessa determinada semântica e sintaxe são o exemplo mais evidente do concreto pensado exposto sobre a forma de texto. Sem esses recursos de objetivação a cultura seria incapaz de ser representada e experimentada.

$\mathrm{Na}$ qualidade de sociedade civil dentro da sociedade civil, a Igreja postula regenerar o seu próprio tecido em primeiro lugar devido aos muitos desgastes sofridos nos conflitos com o Estado. Foi graças a descoberta pela hierarquia católica e dos próprios católicos da relevância do religiosidade católica existir antes e independente do Estado, que esta pode investir na confecção de um território próprio para Igreja experimentar, fortalecer, elaborar e atualizar a sua concepção de mundo à luz de manter-se como promotora do ideário de ordem social e moral.

Com efeito, a opção da hierarquia religiosa por manter-se ao lado do Estado descortina seu interesse em assegurar a sua própria reprodução como parte constitutiva do projeto hegemônico no seio das contradições mais gritantes entre superestrutura e infraestrutura. Mas ela guarda também uma singularidade, que é a necessidade de constante de estar atualizada como um corpo que se auto reproduz, sem ter necessariamente que depender dos recursos materiais espirituais, senão aqueles próprios elaborados em seu âmago para não se deixar distanciar de seu significado e sentido original - o projeto salvífico da igreja. Aqui se revela a capacidade de mobilização autônoma da Igreja para continuar fazer parte da sociedade civil. Munida dessa

\footnotetext{
${ }^{11}$ Hobsbawm afirma que essa estrutura deve estar baseada na capacidade persistente e crescente da espécie humana de controlar as forças de natureza por meio do trabalho manual e mental, da tecnologia e da organização da produção. (HOBSBAWM, 1998. p. 47).
} 
credencial, a Igreja oferece os seus serviços para a validação da organização social e moral existente, bem como alinha o seu corpo de justificação ideológica para dar sustento a construção normativa do Estado.

\section{CONSIDERAÇÕES FINAIS}

Nessa proposta de interpretação descrita, interrogamos o plano da obra de Gramsci para oferecermos uma alternativa de percepção de como opera a Igreja Católica. Longe do esgotamento do tema, tão pouco se pretende impor um modelo pronto para analisar a religião, visto que, assim como outras correntes de pensamento, o marxismo pode ser um holofote parcial que ilumina de algum modo a realidade social. Segundo José Carlos Reis (2000), “nenhuma hipótese é tão totalizante que possa ser assim um ponto de vista do Sol ou de Deus. E quando reivindicam tal amplitude tornam-se ‘totalitárias' e deixam de ser cognitivamente fecundas”. (REIS, 2000, p. 186).

Consideramos pertinente apontar um caminho possível do estudo do cristianismo tendo como aporte teórico o marxismo, mais especificamente, o pensamento de Gramsci. Destarte, é importante salientar antes de tudo, a reflexão de Antonio Gramsci nasce na política, embora não se finde nela - tanto na perspectiva de um revolucionário quanto relacionada às referências a ciência política - , sem deixar de ser um empreendimento intelectual relacionado ao ofício do historiador, embora sua formação de origem fosse na área de linguística. Por isso, a centralidade do conhecimento histórico no pensamento gramsciniano deriva do papel que ele conferia a história em relação ao pensamento e à política. A relação entre História e política é bastante recorrente nos Cadernos do Cárcere, isso porque, para um revolucionário, o conhecimento histórico é essencial para obter êxito no ato de fazer a revolução, visto que, esse conhecimento é constitutivo da filosofia da práxis, portanto, uma condição necessária para a construção de uma vontade política coletiva.

Nesse sentido, Gramsci procura enfatizar o protagonismo do indivíduo na história, considerando que o humano deve ser entendido a partir das necessidades e liberdades tecidas em sua época, isto é, tendo como horizonte as condições objetivas e as ideias do seu tempo. Dessa maneira, compreender o homem presume a percepção da ambiência que atua sobre as ações humanas em determinado período histórico, bem como as expectativas individuais e sociais presentes nos cenários analisados. (TABORDA DE OLIVEIRA; VIEIRA, 2010). 
Tendo como base os caminhos apontados por Antonio Gramsci, outros estudos relacionados a religião, sobretudo do cristianismo, podem ter como referência essa análise marxista, ao levar em conta o estudo da produção da vida material para compreender as práticas culturais, por isso, ele percebe a religião como portadora das contradições que perpassam a sociedade.

Com isso, a análise de Gramsci sobre o fenômeno religioso não se prende a análises deterministas, visto que ele flexibiliza seu pensamento tendo em vista a forma como é experimentada a religião por parte do indivíduo e como isso se relaciona com o todo. Exemplo disso é sua visão sobre a Igreja católica, que, apesar de ser umas das engrenagens essenciais do Estado durante a época medieval e moderna, não desconsiderou de sua a reprodução orgânica como instituição, sem descuidar da aliança necessária para assegurar sua condição no bloco de poder.

Devendo reconhecer, entretanto, a nova situação de estar subsumida ao poder civil - tendo a função de preservar a hegemonia da classe fundamental -, na prática atuando de maneira autônoma, dentro de certo limite, a Igreja recorre ao seu projeto de salvação para legitimar em última instância sua razão de existir. Uma vez preservado o interesse de reprodução da hegemonia, a Igreja persevera, enquanto aglutina força para validar seu holismo, sem se deixar reduzir ao parâmetro do conflito de classes.

\section{REFERÊNCIAS BIBLIOGRÁFICAS:}

FEUERBACH, Ludwig (1804-1872). A Essência do Cristianismo. Petrópolis: Vozes, 2007.

GRAMSCI, Antonio. Cadernos do Cárcere, vol. 4, tradução de Carlos Nelson Coutinho. Rio de Janeiro: Civilização Brasileira, 2007.

GRAMSCI, Antonio. Cadernos do Cárcere, vol. 1, edição de Carlos Nelson Coutinho, com a colaboração de Luiz Sérgio Henriques e Marco Aurélio Nogueira. Rio de Janeiro: Civilização Brasileira, 1999.

GRAMSCI, Antonio. Concepção dialética da história. 3. Ed. Rio de Janeiro: Civilização Brasileira, 1978.

GRAMSCI, Antonio. Os intelectuais e a organização da cultura. Rio de Janeiro: Civilização Brasileira, 1982.

GRUPPI, Luciano. O conceito de Hegemonia em Gramsci. 3. Ed. Rio de Janeiro: Editora Graal, 1991.

HOBSBAWM, Eric. Sobre História. São Paulo: Editora Companhia das Letras, 1998. KAUTSKY, Karl. A Origem do Cristianismo. Rio de Janeiro: Civilização Brasileira, 2010. 
LEÃO XIII. Rerum Novarum: carta encíclica sobre a condição dos operários. Tradução de Manuel Alves da Silva, S. J. São Paulo: Paulinas, 1997.

LÖWY, Michael. Marx e Engels como sociólogos da religião. Lua Nova, São Paulo, n. 43, p. 157-170, 1998. Disponível em: <http://www.scielo.br/scielo.php?script=sci_arttext\&pid=S0102-

64451998000100009\&lng=en\&nrm=iso>. Acesso em: 29 de abril de 2020.

LÖWY, Michael. Marxismo e religião: ópio do povo?. A teoria marxista hoje. Problemas e perspectivas. Buenos Aires, p. 298-315, 2007. Disponível em: $\langle$ http://biblioteca.clacso.edu.ar/clacso/formacionvirtual/20100715080929/cap11.pdf $>$. Acesso em: 28 de abril de 2020.

MARX, Karl. Critica da Filosofía do Direito de Hegel. São Paulo: Boitempo Editorial, 2005.

MARX, Karl; ENGELS, Friedrich. A Ideologia Alemã. São Paulo: Martins Fontes, 2001.

PORTELlI, Hugues. Gramsci e a Questão Religiosa. 2. Ed. São Paulo: Paulinas, 1984.

REIS, José Carlos. "Annales e marxismo: 'programas históricos' complementares, antagônicos ou 'diferenciados'?”. In: REIS, José Carlos. Escola dos Annales: A inovação em História. Rio de Janeiro: Paz e Terra, 2000, p. 166-1167.

TABORDA DE OLIVEIRA, M. A.; VIEIRA, C. E; THOMPSON E GRAMSCI: história, política e processos de formação. Educação \& Sociedade (Impresso), v. 31, p. 519-537, 2010.

VIEIRA, C. E. O historicismo gramisciano e a pesquisa em educação. Perspectiva (Florianópolis), Florianópolis, n. 20, p. 31-51, 1995. 